\title{
Evaluation of Claviceps purpurea isolates on wheat reveals complex virulence and host susceptibility relationships
}

Article

Accepted Version

Menzies, J. G., Klein-Gebbinck, H. W., Gordon, A. and O'Sullivan, D. M. (2017) Evaluation of Claviceps purpurea isolates on wheat reveals complex virulence and host susceptibility relationships. Canadian Journal of Plant Pathology, 39 (3). pp. 307-317. ISSN 0706-0661 doi: https://doi.org/10.1080/07060661.2017.1355334 Available at https://centaur.reading.ac.uk/72359/

It is advisable to refer to the publisher's version if you intend to cite from the work. See Guidance on citing.

Published version at: http://dx.doi.org/10.1080/07060661.2017.1355334

To link to this article DOI: http://dx.doi.org/10.1080/07060661.2017.1355334

Publisher: Taylor and Francis

All outputs in CentAUR are protected by Intellectual Property Rights law, including copyright law. Copyright and IPR is retained by the creators or other copyright holders. Terms and conditions for use of this material are defined in the End User Agreement. 


\section{CentAUR}

Central Archive at the University of Reading

Reading's research outputs online 
1 Subject category: GENETICS AND RESISTANCE / GÉNÉTIQUE ET RÉSISTANCE

2

3

4 Evaluation of Claviceps purpurea isolates on wheat reveals complex virulence and host 5 susceptibility relationships.

6

7 JAMES G. MENZIES ${ }^{*}$, HENRY W. KLEIN-GEBBINCK ${ }^{2}$, ANNA GORDON $^{3}$, and 8 DONAL M. O'SULLIVAN ${ }^{4}$

9

$10{ }^{1}$ Agriculture and Agri-Food Canada, Morden Research and Development Centre, 101 Route

11 100, Morden MB, R6M 1Y5, Canada

$12{ }^{2}$ Agriculture and Agri-Food Canada, Beaverlodge Research and Development Centre,

13 Beaverlodge, AB, TOH OCO, Canada

$14{ }^{3}$ National Institute of Agricultural Botany, Huntingdon Road, Cambridge, CB3 OLE, United

$15 \quad$ Kingdom

$16{ }^{4}$ School of Agriculture, Policy and Development, University of Reading, Whiteknights, Reading,

17 RG6 6AR, United Kingdom.

20 Correspondence to: J.G. Menzies. E-mail: jim.menzies@ canada.ca

21

22 (Accepted : XX XX XXXX)

23 
24 Abstract: Ergot of cereals, caused by Claviceps purpurea, results in yield loss and downgrading 25 of infested grain because of toxic alkaloids in the sclerotia. Resistant wheat genotypes are

26 known, but their effectiveness against different $C$. purpurea isolates over geographic regions has

27 not been studied. The objective was to examine the pathogenic variability among isolates of $C$.

28 purpurea on wheat lines differing in resistance. Under controlled environmental conditions,

29 fourty one single spore isolates of $C$. purpurea were developed from Canadian and United

30 Kingdom collections and inoculated onto a set of wheat genotypes composed of durum wheat

31 lines 'Melita', 'Kyle', and 9260B-173A, and hexaploid spring wheat lines 'Cadillac', 'Vista',

32 'Kenya Farmer', 'Lee' and HY630. Honeydew production and weight of sclerotia produced per

33 spike were assessed. There were significant differences among the wheat genotypes for overall

34 reactions to the pathogen isolates, and among pathogen isolates for geographic origin and host

35 origin. Twenty virulence phenotypes were identified using the honeydew production data, and 23

36 virulence phenotypes identified using the sclerotial weight data from the 41 isolates. The

37 existence of different virulence phenotypes indicates that variability in virulence exists in

38 populations of $C$. purpurea, and knowledge of virulence phenotypes is necessary to effectively

39 breed for resistant commercial lines.

40

41 Keywords : Claviceps purpurea, Triticum aestivum, T. aestivum var. durum, wheat, virulence, 42 genetic variability 
Introduction

44 Ergot of cereals, caused by Claviceps purpurea (Fr.) Tul., is a common disease in holoarctic regions of the world (Linder, 1948; Gaudet et al., 2000). It's most conspicuous symptom is the formation of dark purple to black ergot bodies or sclerotia that are visible on infected cereal spikes, or in the harvested grain. This disease does not often result in large yield losses, but can have a large impact on cereal production because of the downgrading of grain infested with sclerotia (Canadian Grain Commission, 2012). The ergot bodies contain various alkaloids toxic to humans and livestock, which can cause severe health problems if ingested. Ergot is often considered a disease of the Middle Ages, as it was common during that period and resulted in many thousands of people dying from consuming ergot infested grain. As more became known about this disease, such as how to control ergot and avoid contaminated grain, it became less of a problem. The last major outbreak of ergotism affecting people was recorded in 1951 in France (Gabbai et al., 1951).

Ergot was not reported at significant levels throughout most of the 1980s and 1990s on the Canadian Prairies. In 1999, surveys conducted by the Grain Research Laboratory as part of the Harvest Survey Program of the Canadian Grain Commission (Canadian Grain Commission 2013) revealed that $12 \%$ of all samples of Canadian Western Red Spring (CWRS) wheat and $4 \%$ of Canada Western Amber Durum (CWAD) contained ergot bodies. In Saskatchewan, 17\% of the CWRS wheat delivered to the elevators was infested with ergot. Ergot was a problem in Manitoba in 2005, when $10 \%$ of CWRS wheat samples were infested with ergot sclerotia (Menzies \& Turkington, 2014). This was followed by ergot infestation levels of CWRS wheat samples in Alberta, Saskatchewan and Manitoba of 12\%, 15\% and 13\%, respectively in 2008. These levels declined in 2009, but in 2011, ergot infestation levels rose to $29 \%$, $19 \%$ and $15 \%$ in 
Alberta, Saskatchewan and Manitoba, respectively. The 2012 levels of ergot infestation of CWRS wheat declined by $50 \%$ or more from 2011, but in Alberta and Saskatchewan, they were still three to five times greater than what was reported in 2002 to 2007 . The ergot infestation of grain on the Canadian prairies has resulted in decreased returns to farmers as ergot infested grain must have the ergot bodies removed, or become downgraded or rejected at point of sale, and increased risk to livestock as some of the ergot infested grain is used as feed.

The increased incidence and severity of this pathogen in fields of wheat in western Canada has led to greater interest in the biology and control of this disease. The identification of possible sources of resistance to $C$. purpurea in wheat, and the development of resistant commercial lines are being explored. Studies examining the presence of ergot resistance in lines of wheat have been conducted by Platford \& Bernier (1970, 1976), Puranik \& Mathre (1971), Darlington \& Mathre (1976), Watkins \& Littlefield (1976), Coley-Smith \& Watkinson (1987), Pageau et al. (1994), Menzies (2004), and Bayles et al. (2009). Puranik \& Mathre (1971) inoculated male sterile lines of barley and wheat and observed no differences among the lines in terms of percentage of florets infected. However, the other studies observed differences in resistance among lines of wheat, although the most resistant lines were often not suitable for commercial production. These results are significant in that they reveal that differences in susceptibility among genotypes of wheat to $C$. purpurea do occur, even if some of the differences are not great.

The identification of lines of wheat resistant to $C$. purpurea is a good step towards the development of resistant commercial lines, but often only a few isolates of the pathogen have been used in identifying resistant genotypes. The effectiveness of these resistant sources against all or the majority of the strains in a local area, or from different geographic regions, has not 
89 been addressed. Variability in pathogenicity of different strains of $C$. purpurea has not been

90

91

92 extensively studied so little is known about the amount of pathogenic variability that a resistant host line may encounter in nature. Campbell (1957) studied the host specificity of 423 isolates of this fungus on 38 different host species and observed no host specificity among the isolates. $\mathrm{He}$ reported that each grass species became infected and concluded that indigenous and forage grasses constituted a reservoir of ergot inoculum for cereal grain hosts. Darlington et al. (1977) inoculated 48 isolates of the pathogen onto eight lines of barley and four lines of wheat to determine if specific biotypes or races could be identified. They did not find good evidence of the occurrence of specific races, but did observe differences in the percent infection of florets among the isolates. Cagaš \& Macháč (2002) inoculated seven lines of Kentucky bluegrass with three European isolates and one isolate from the U.S.A. and found significant differences in the number and weight of sclerotia between the European isolates and the isolate from the U.S.A.

The isolate from the U.S.A. produced more and heavier sclerotia than the European isolates. The differences in percent infection of florets of isolates of C. purpurea led Darlington et al. (1977) to recommend that plant breeders use a mixture of isolates in screening germplasm for resistance to ergot.

The objective of this research was to determine if pathogenic variability exists among different isolates of $C$. purpurea collected from Canada and the United Kingdom on lines of wheat differing in their levels of susceptibility/resistance.

\section{Materials and methods}

Pathogen isolates collection and maintenance 
111 Thirty seven samples of $C$. purpurea collected from Manitoba, Saskatchewan and Alberta,

112 Canada, and four cultures from the United Kingdom were used (Table 1). Twenty six of the 37

113 samples from Canada were obtained as sclerotia in grain samples from Randy Clear (Canadian

114 Grain Commission, Winnipeg, Canada) as part of the CGC's 2000 harvest survey program. Four

115 sclerotia were collected from field plots at the University of Manitoba, Winnipeg, MB, in 1996,

116 and 7 sclerotia were collected during annual barley, oat and wheat disease surveys in 1996, 1997

117 and 2005. The sclerotia were used to produce mycelial isolates. Each sclerotium was surface

118 sterilized by immersion and shaking in 95\% ETOH for 30 seconds followed by igniting the

119 sclerotia with a flame. The surface sterilized sclerotia were then cut into small pieces using a

120 sterile scalpel. Pieces of the sclerotia were placed onto acidified malt extract agar [6 g dextrose

121 (Fisher Scientific), $3 \mathrm{~g}$ malt extract, $3 \mathrm{~g}$ yeast extract and $12 \mathrm{~g}$ bacto agar (Becton, Dickenson and

122 Company) in $1 \mathrm{~L} \mathrm{H}_{2} \mathrm{O}$, acidified with $450 \mu \mathrm{L}$ of $2.5 \%$ lactic acid after autoclaving] in Petri

123 dishes and incubated for up to one week or until mycelium started to grow on the agar at room

124 temperature $\left(21^{\circ} \mathrm{C}\right)$ under ambient light. Small plugs of agar with growing mycelium were

125 transferred to new malt agar Petri dishes, allowed to grow for a few days at room temperature,

126 and then maintained at $5^{\circ} \mathrm{C}$. The four cultures originating in the United Kingdom were supplied

127 as mycelial isolates and were also maintained on malt agar at $5^{\circ} \mathrm{C}$.

Single spore isolates of each culture were established by inoculating $125 \mathrm{~mL}$ of $2 \%$

129 potato sucrose broth in a $500 \mathrm{~mL}$ Erlenmeyer flask with a small agar plug with growing

130 mycelium and incubating the culture for 14 days at room temperature under ambient light on a

131 rotary shaker at $150 \mathrm{rpm}$. The mature cultures were filtered through sterile cheesecloth, and the

132 spore suspensions diluted to $10^{3}$ spores $/ \mathrm{mL}$ with the aid of a haemocytometer. An aliquot of each

133 spore suspension was streaked on $2 \%$ water agar using an inoculation loop, and incubated at 
134 room temperature under ambient light for $24 \mathrm{~h}$. Single germinating spores were identified using a 135 dissecting microscope, and the single spores transferred into Petri dishes containing malt extract 136 agar. The single spore isolates were maintained on malt extract agar slants at $5^{\circ} \mathrm{C}$. those of Pažoutová et al. (2015) by K.A. Seifert and M. Liu (Ottawa Research and Development Centre, AAFC-AAC, Ottawa, ON, Canada).

\section{Inoculum preparation}

141 Inoculum was produced following the procedure of Menzies (2004, stored for a maximum 2 mo

142 at $5^{\circ} \mathrm{C}$ until used (Platford \& Bernier 1976). An aliquot of each sucrose spore suspension was

143 mixed in distilled water with one drop of Tween 20 (polyethylene glycol sorbitan monolaurate)

144 per $\mathrm{L}$ to make a final concentration of $10^{4}$ spores per $\mathrm{mL}$ as determined using a haemocytometer, 145 prior to use as inoculum (Platford \& Bernier 1970, 1976).

146 Wheat differential set

147 A differential set of spring wheat lines which varied in their response to infection by $C$. purpurea 148 was established based on the assessments by Platford \& Bernier (1970, 1976) and Menzies

149 (2004). The differential set included the durum wheat (Triticum aestivum L. var. durum) lines 150 'Melita', 'Kyle', and 9260B-173A, and the hexaploid spring wheat (T. aestivum L.) lines 151 'Cadillac', 'Vista', 'Kenya Farmer' 'Lee' and HY630. 'Melita', 'Cadillac' and 'Vista' were 152 chosen as susceptible genotypes, and the others were selected because they had shown some 153 level of resistance in previous tests (Platford \& Bernier 1970, 1976; Menzies 2004).

\section{Inoculation procedure}


155 Wheat lines were sown separately into $15 \mathrm{~cm}$ pots and grown in growth cabinets at a temperature 156 of $16^{\circ} \mathrm{C}$ night $/ 22^{\circ} \mathrm{C}$ day with a $15 \mathrm{~h} / 9 \mathrm{~h}$ light/dark period. Twelve seeds were sown per pot. Ten

157 to 12 spikes were allowed to develop per pot, and 9 spikes inoculated per pot. The spikes were 158 inoculated prior to anthesis (Platford \& Bernier 1970), when the spikes had just completely 159 emerged from the boot. Twenty florets were inoculated per spike by selecting five healthy 160 spikelets on each side of the spike and injecting a spore suspension into the primary and 161 secondary florets on each spikelet using a syringe and hypodermic needle to fill the florets 162 (Campbell 1957; Platford \& Bernier 1976). The spikelet below the group of inoculated spikelets 163 was removed as a marker for the inoculated spikelets (Menzies 2004). Three spikes per pot were 164 inoculated from four separate pots representing four replicates of three spikes each for each 165 fungal isolate on each wheat line.

167 inoculation using a scale from 1 to 4 with $1=$ none visible, $2=$ honeydew confined within the 168 glumes, 3 = honeydew exuding from the florets in small drops, and $4=$ large drops of honeydew 169 running down the spike (Menzies 2004). At maturity, each spike was harvested and threshed by 170 hand. Total weight in mg of sclerotia per spike was recorded.

\section{Statistical analysis}

172 Analysis of variance was performed on honeydew production and sclerotial weight data to

173 determine the relative contribution of isolate by differential interaction to the total variance 174 comprising of replicates, the simple effects and interaction. The model least square means were 175 calculated and used to tabulate the response of the differential wheat lines to the different 176 isolates. 
Correspondence analysis (CA; Savary et al. 1994) was performed to determine the association between the factors (differential lines, isolate sampling location and the isolate host source) and the variables honeydew production and sclerotial weight because honeydew production values were categorical and ordinal in nature. The median honeydew production and mean total sclerotial weights were determined for each pot. Medians and means were converted into classes. The classes of the honeydew production were determined by the class ranges of 1 , 1.5-2.5, $3-3.5$ and 4 for the classes $\mathrm{H} 1, \mathrm{H} 2, \mathrm{H} 3$ and $\mathrm{H} 4$ respectively. Mean sclerotial weights were also converted to classes by assigning the data to classes $\mathrm{Sc} 1, \mathrm{Sc} 2, \mathrm{Sc} 3$ and $\mathrm{Sc} 4$ with the end points of 0-35mg, >35-130 mg, >130-350 and >350. For both categorical variable $\mathrm{H}$ and $\mathrm{Sc}$, contingency tables were constructed with isolate sampling location ( $\mathrm{AB}, \mathrm{SK}, \mathrm{MB}$ and $\mathrm{UK})$, isolate host source (Wht for hexaploid spring wheat, Dur for durum wheat, Tri for triticale, Bar for barley, BG for blackgrass, Oat for oat and Rye for rye), and the wheat differential lines. Tests of independence for each contingency table were performed. In addition, a test of independence was calculated for the categorical variables for honeydew production and sclerotial weight.

Correspondence analysis is a multivariate statistical technique for creating an ordination similar to principal component analysis (PCA). In contrast to PCA which is based on Euclidian distances, CA uses the chi-square distances between rows. As in PCA, eigenvalues and eigenvectors were determined, and coordinates determined by weighing the rows of the contingency tables by the first and second eigenvectors. The calculations of the analysis were performed using the package "ca" in R (R Core Team 2016). To determine the significance of the first eigenvalue, a Monte Carlo simulation was performed on 1000 permutations of the dependent variable and the eigenanalysis performed on each resulting contingency table with the p-value of the test statistic compared to the given percentile of the simulations. 
201 Results

202 The different isolates of $C$. purpurea caused a wide range of disease symptoms on the different 203 wheat genotypes. Honeydew production ratings ranged from 1 to 4 (Table 2), and the weight of 204 sclerotia produced on a spike ranged from $0 \mathrm{mg}$ to more than $1000 \mathrm{mg}$ (Table 3). A test of 205 independence for a contingency of honeydew production versus sclerotial weight per spike 206 indicated a significant positive association $\left(\mathrm{X}^{2}=0.864, \mathrm{P}<0.0001\right)$.

ANOVA indicated that the effects of the wheat differential lines, pathogen isolates and

208 the wheat differential line by pathogen isolate interactions were significant $(\mathrm{P}<0.0001)$ for both 209 honeydew production and sclerotial weights. Differential lines, isolates and their interaction 210 accounted for $32 \%, 39 \%$ and $29 \%$ of the total treatment sum of squares for honeydew 211 production, respectively. For log transformed sclerotial weights, the sum of squares for 212 differential lines accounted for $40 \%$ of the total, $33 \%$ for the isolates, and $27 \%$ for the 213 interaction.

The CA involving wheat differential line, isolate sampling location and isolate host

215 source for honeydew production is presented in the plot in Figure 1. The graph is derived from 216 the eigenanalysis of these contingency tables. The first eigenvalue accounted for $73.2 \%$ of the 217 variation inherent in the contingency tables and the second eigenvalue accounted for $23.2 \%$ of 218 the variation. The H1 to H4 points on the honeydew biplot (Figure 1) are based on column scores 219 derived from the eigenanalysis of the counts of the contingency tables of the three factors. The 220 path from $\mathrm{H} 1$ to $\mathrm{H} 4$ indicates increasing honeydew production with means of 1.0, 2.0, 3.0 and 2214.0 for $\mathrm{H} 1, \mathrm{H} 2, \mathrm{H} 3$ and H4, respectively. Contingency table analysis and Pearson's chi square 
222 analysis indicated significant differences $(\mathrm{P}<0.0001)$ among the wheat differential lines, the 223 isolate sampling locations, and the isolate host sources. 9260B-173A had significantly lower

224 honeydew production than the other lines, followed by 'Kenya Farmer'. This was followed by a 225 group of lines consisting of HY630, 'Kyle', 'Lee', 'Vista' and 'Cadillac' which had lower 226 honeydew production than 'Melita'. Isolates from the UK had higher honeydew production than 227 those from Alberta, which were higher than those from Saskatchewan and Manitoba, which did 228 not differ. Isolates sourced from rye had greater honeydew production than the isolates sourced

229 from other hosts, with durum wheat isolates having higher honeydew production than the 230 remaining hosts isolates. The Blackgrass, triticale and oat isolates were combined for analysis 231 because of low isolate numbers, and this combination of isolates had higher honeydew 232 production than the wheat and barley sourced isolates. The wheat isolates had greater honeydew 233 production than the barley isolates. The first eigenvalue $(0.1541)$ was significant $(\mathrm{P}<0.001)$ as 234 determined by Monte Carlo at the 99.9 percentile of 0.0131 .

Correspondence analysis provides a graphical representation of the trends in a 236 contingency table, unlike analysis of variance. The eigenanalysis resulted in a number of axes 237 that account foremost of the inertia (variance) present in the contingency table. Only the first two 238 axes were used. Scores for each of the rows and columns are determined for each axis. These 239 scores are used in the biplot. For a given factor, the distance of a point from the origin gives a 240 measure of the strength of this point. In addition, a way to interpret the graphs is to draw lines 241 from the origin to a disease point (e.g. H1) and determine the angle from this line to that formed 242 by two independent sources [e.g. sources (wheat and barley)]. If the angle is acute, then the 243 profiles for the two variables are similar and becomes more dissimilar as the angle increases. 244 Alternatovely, the relative frequencies of the honeydew categories in the source sample may be 
245 determined by drawing a line through the origin to the source sample (e.g. barley) and looking at 246 the point on this line by projecting a perpendicular to this line to the disease category points.

247 Frequencies of points on the line formed by the perpendicular projections from the point of a 248 disease category on the same side from the origin as the corresponding source point occur more 249 often than average profile with distance from the origin, and less often on the opposite side. For 250 example, using the latter method using rye and barley, the frequency of honeydew level H4 251 252 253

occurred more often than average using isolates derived from rye and H1 less often than average, whereas $\mathrm{H} 1$ occurred more often than average using isolates from barley and less often than average for $\mathrm{H} 4$.

The CA involving wheat differential line, isolate sampling location and isolate host source for sclerotial weight is presented in the plot in Figure 2. The graph is derived from the eigenanalysis of these contingency tables. The first eigenvalue accounted for $80.9 \%$ of the variation inherent in the contingency tables and the second eigenvalue accounted for $16.3 \%$ of the variation. The Sc1 to Sc4 points on the biplot (Figure 2) are based on column scores of the contingency tables of the three factors. The biplot is derived from the eigenanalysis of these contingency tables. The path from Sc1 to Sc4 indicates increasing sclerotial weight production with means of $11.2 \mathrm{mg}$ for Sc1, 80.1 for Sc2, 226.9 for Sc3 and $610.5 \mathrm{mg}$ for Sc4. Contingency table analysis and Pearson's chi square analysis indicated significant differences $(\mathrm{P}<0.0001)$ among the different wheat lines, the isolate sampling locations, and the isolate host sources. The wheat lines were all different from each other in terms of sclerotial weight, with 9260B-173A having the lowest sclerotial weight and 'Cadillac' having the greatest weight based on the distribution in the contingency table. The isolate sampling locations also differed in sclerotial weight with the UK having the highest sclerotial weights and Manitoba having the lowest. 
Isolates sourced from rye had greater sclerotial weight production than the isolates sourced from other hosts, with durum wheat isolates having higher sclerotial weight production than the remaining host isolates. The wheat isolates had greater sclerotial weight production than the barley isolates. The first eigenvalue $(0.1504)$ of this analysis was also significant $(\mathrm{P}<0.001)$ as determined by Monte Carlo at the 99.9 percentile of 0.0126 .

The phenotypic data for the 41 individual isolates of $C$. purpurea on the eight wheat lines for honeydew production are presented in Table 2. The susceptible reaction for honeydew production was set at a rating of 2.1 or greater because this is just above the $\mathrm{H} 2$ point in the CA. The number of pathogen isolates that caused a susceptible or compatible reaction on the different wheat lines was as follows: 8 isolates $(20 \%)$ on 9260B-173A, 30 isolates $(73 \%)$ on 'Kyle', 40 (98\%) on 'Melita', 22 (54\%) on HY630, 17 (41\%) on 'Kenya Farmer', 28 (68\%) on 'Lee', 30 (73\%) on 'Vista', and $30(73 \%)$ on 'Cadillac'. There were 20 different virulence phenotypes identified as separated by resistant and susceptible reactions using the honeydew production data. The most common virulence phenotype possessed by 12 pathogen isolates (isolates 44-2, 89-1, 90, 93-2, 95, 101 148, 155, 169-6, 179-1, 179-2 and UK 03-20-1) had virulence to all the wheat lines except 9260B-173A (Table 2). The five isolates 7-1, 7-2, 125, 128 and 166-1 had virulence to 'Kyle', 'Melita', 'Lee', 'Vista' and 'Cadillac'. The UK isolates UK 03-43-1, UK 04-02-1 and UK 04-97-1 and isolate 169-1 possessed virulence to all the wheat lines. There were three groups of two isolates each, isolates 22 and 38, isolates 40 and 100 and isolates 172 and 192-1, which had the same virulence phenotype, The other 14 isolates in this study had unique virulence phenotypes.

The phenotypic data for weight of sclerotia for the 41 individual isolates of $C$. purpurea on the eight wheat lines is presented in Table 3. A wheat line was considered susceptible to an 
291 individual isolate if $81 \mathrm{mg}$ or more of sclerotia were produced per spike because this is just 292 above the Sc2 point in the CA. The number of isolates causing a susceptible or compatible 293 reaction on the different wheat lines were as follows: 5 isolates (12\%) on 9260B-173A, 12 294 isolates (29\%) on 'Kyle', $33(80 \%)$ on 'Melita', $23(56 \%)$ on HY630, 18 (44\%) on 'Kenya 295 Farmer', 30 (73\%) on 'Lee', 37 (90\%) on 'Vista', and 32 (78\%) on 'Cadillac'. There were 23 296 different virulence phenotypes identified using the sclerotial weight data. The most common 297 virulence phenotype possessed by 6 isolates (isolates 90, 93-2, 101, 148, 179-1 and 179-2) had 298 virulence to all the wheat lines except 9260B-173A (Table 3). There were 2 sets of five isolates 299 which possessed virulence to all the wheat lines except 9260B-173A and 'Kyle' (isolates 44-2, 89-1, 95, 155 and 169-6), or virulence to 'Melita', 'Lee', 'Vista' and 'Cadillac' (isolates 7-2, 29$3012,33-2,85$ and 128). There were five groups of two isolates each, isolates 7-1 and 115, isolates 30240 and 77, isolates 169-1 and UK 03-43-1, isolates 7-3 and 138, and isolates 125 and 166-1, 303 which had the same virulence phenotype. Fifteen of the 23 virulence phenotypes were 304 represented by only one isolate including isolate UK 04-02-1, which was the only isolate to have 305 virulence to all the wheat differential lines.

\section{Discussion}


313 Variability among the isolates of $C$. purpurea was evident for honeydew production and

314 sclerotial weight per spike, which is in agreement with previous studies (Platford \& Bernier,

315 1976. Pathogenic variability was observed on each wheat line used in these experiments,

316 indicating it was because of genetic variation among isolates. These two disease symptoms

317 represent two different aspects of the disease cycle of $C$. purpurea. The honeydew is important

318 in secondary spread of the pathogen (Gaudet et al., 2000) and a reduction in honeydew would

319 likely lead to reduced spread. The weight of sclerotia per spike provides an indication of the

320 success of the pathogen in reproducing on the host. The weight of sclerotia per spike reflects the

321 success of the pathogen in diverting plant resources, and considers the role of larger, heavier

322 sclerotia in pathogen reproduction. Cooke \& Mitchell (1966) and Rapilly (1968) observed

323 positive linear relationships between the size of sclerotia and the number of clavae produced by

324 the sclerotium. The number of clavae produced would influence the number of ascospores

325 produced and released from a sclerotium. Therefore, lighter sclerotia would result in fewer

326 ascospores being produced to start infections in the next season.

Isolates from the United Kingdom had higher honeydew ratings and greater sclerotial

328 weights per spike than isolates from Alberta, which in turn, were more severe than isolates from

329 Saskatchewan and Manitoba. This suggests that the U.K. isolates of $C$. purpurea have greater

330 potential to cause disease than the western Canadian isolates and the Alberta isolates had a

331 greater potential than the Saskatchewan and Manitoba isolates. These results suggest the

332 severity of disease caused by isolates of $C$. purpurea may vary with geographic origin of the

333 isolate.

Claviceps purpurea isolates originating from different hosts varied in the severity of disease they caused on the 8 wheat differential lines. Isolates from rye had significantly greater 
honeydew production and weight of sclerotia per spike than the other isolates, while those from barley had significantly lower honeydew production and weight of sclerotia per spike. These results suggest that the amount of disease caused by an isolate of $C$. purpurea may be influenced by the host of origin. The hosts of origin in this study are known to vary in their susceptibility to C. purpurea. Platford \& Bernier (1976) listed the susceptibility of the different crop species in the following order of decreasing susceptibility: rye, triticale, wheat, barley and oats. Possibly, host species which are more susceptible or prone to infection allow the more rapid spread of more virulent isolates, i.e. those with greater honeydew production, as compared to less virulent isolates of $C$. purpurea, once crop plants become infected. This more rapid spread of infection by the more virulent isolates would result in their sclerotia becoming predominant in infested grain samples from the field. The positive association between honeydew production and sclerotial weight per spike would lead to greater weights of sclerotia being produced by the more virulent isolates on these more susceptible host crops. The nature of our sampling technique, in which one sclerotium is sampled from a grain sample, likely results in the dominant or common genotypes, or in our case the more virulent genotypes, being collected more often than the less common or less virulent isolates. Popovic \& Menzies (2006), working with Ustilago tritici, suggested that if one genotype per field is sampled, a dominant genotype would be more commonly collected than other genotypes. Other hosts which are not as susceptible or prone to infection by $C$. purpurea as rye may not be so conducive to the rapid secondary spread of more virulent isolates, and the sclerotia collected in infested grain of these crops may be more reflective of the pathogen isolates that originally invaded the field from sporulating sclerotia or neighbouring grasses. 
The development of a differential host series for a pathogen is dependent on identifying lines with different responses to the pathogen. The inoculation of the eight wheat lines with 41 isolates confirmed that the lines do differ in their reactions to $C$. purpurea as previously reported by Menzies (2004) and Platford \& Bernier (1970, 1976). There are other wheat genotypes that have been reported to show resistance to C. purpurea, which could be considered for inclusion in

363 a more comprehensive differential set. For instance, the winter wheat line 'Robigus' has recently 364 been shown to have lower average sclerotium weight and sclerotial weight per ear than other winter wheat lines (Gordon et al. 2015). It is also important to note that the resistance in our differential wheat lines has not been characterized, and some of these lines may possess more than one gene

367 for resistance, or some of the same genes for resistance. The wheat lines used in this study lack the 368 sophistication and refinement of a near-isogenic set of lines, but nevertheless, provide useful 369 information.

371 vertical resistance interaction (i.e. a gene for gene mechanism) is operating in this pathosystem 372 (Kranz 2003) and honeydew production and/or sclerotial weight may be used to determine 373 virulence phenotypes of $C$. purpurea. The division of pathogen isolate by host genotype 374 interactions into avirulent (resistant) or virulent (susceptible) reactions was set at a honeydew 375 production rating of 2.1 or higher and a sclerotial weight per spike of $81 \mathrm{mg}$ or higher being 376 virulent reactions. The honeydew production data separated the 41 isolates into 20 different 377 virulence phenotypes and the sclerotial weight data separated the isolates into 23 virulence 378 phenotypes. The most common virulence phenotype for both honeydew production and sclerotial 379 weight per spike possessed virulence to all wheat differential lines except 9260B-173A. Four isolates possessed virulence to all the wheat differential lines for honeydew production and one 
381 isolate for sclerotial weight per spike. Some of the virulence phenotypes displayed a very good

demarcation between virulence and avirulence such as isolate 90 with a honeydew production rating of 1 on 9260B-173A and 3.7 on 'Cadillac' and sclerotial weight per spike of $9 \mathrm{mg}$ on 9260B-173A and $1179 \mathrm{mg}$ on 'Cadillac'. Other isolates did not show such a stark difference between virulence and avirulence, with some honeydew production and sclerotial weight values being close to the demarcation points. For instance, isolates 102 and 172 had a number of honeydew production and sclerotial weight per spike values which were close to being either avirulent or virulent. Our knowledge of the genetics of the wheat $-C$. purpurea pathosystem is very limited and the interaction of pathogen isolates with differential host lines yielding reactions that are close to the avirulent/avirulent demarcation point is not uncommon in other pathosystems such as the oat-crown rust pathosystem (Menzies, unpublished data). In the wheat (T. aestivum) - leaf rust [Puccinia recondita Roberge ex Dezmaz. f. sp. tritici (Eriks. \& Henn.)] pathosystem, Kolmer \& Dyck (1994) observed that the expression of resistance and avirulence genes was highly dependent on the genotypes of the host lines and rust isolates involved in the interactions. These two rust pathosystems have the luxury of near-isogenic host lines to study these reactions. As previously mentioned, the genetics of the eight wheat differential lines used in this study are not well known and it is possible that the genetics of resistance to C. purpurea of these lines may be complex. Platford et al. (1977) studied the genetics of resistance to $C$. purpurea in 'Kenya Farmer' and determined that a gene or genes for resistance which influence honeydew production and frequency and size of sclerotia was located on chromosome $6 \mathrm{~b}$, but genes on other chromosomes also influenced sclerotium size and honeydew production. Gordon et al. (2015) studied the resistance to C. purpurea in the winter wheat line 'Robigus' and identified interacting QTL that influence the size and weight of sclerotia, but the majority of the 


\section{Acknowledgements}

424 Funding from the Canadian Seed Growers' Association, the Biotechnology and Biological

425 Sciences Research Council, U.K., and AAFC's Growing Forward 2 for a research network on 
426 emerging mycotoxins, and critical review of a manuscript draft by Dr. Robert Conner are

427 gratefully acknowledged. Technical support was provided by C. Saramaga, Z. Popovic, R.

428 Dueck, J. Gruenke, A. Stern, S. Thomson and T. Dykstra.

\section{References}

431 Bayles R, Fletcher M, Gladders P, Hall R, Hollins W, Kenyon D, Thomas J, 2009. Towards a sustainable whole-farm approach to the control of ergot. Project Report No. 456 to the Home Grown Cereals Authority, Stoneleigh Park, Warwickshire, U.K. 170 pages.

Cagaš B, Macháč R. 2002. Different pathogenicity of ergot isolates [Claviceps purpurea (Fr.) Tul.] on Kentucky bluegrass (Poa pratensis L.). Plant Prot Sci. 38: 18-22.

Campbell WP, 1957. Studies on ergot infection in gramineous hosts. Can J Bot. 35: 315-320.

Canadian Grain Commission. 2012. The Official Grain Grading Guide. http://grainscanada.gc.ca/oggg-gocg/04/oggg-gocg-4f-eng.htm (Accessed 08/05/2013).

439 Canadian Grain Commission. 28 May 2013. Harvest survey of Canadian grain quality [online]. Available from http://www.grainscanada.gc.ca/quality-qualite/hsp-per/hs-er-eng.htm [accessed 30/09/2013].

442 Coley-Smith JR, Watkinson L. 1987. Susceptibility of durum wheat cultivars to ergot disease. Ann Appl Biol. 110: 162-163.

444 Cooke RC, Mitchell DT. 1966. Sclerotium size and germination in Claviceps purpurea. Trans 445 Brit Mycol Soc. 49: 95-100. 
446

447

448

449

450

451

452

453

454

455

456

457

458

459

460

461

462

Darlington LC, Mathre DE. 1976. Resistance of male sterile wheat to ergot as related to pollination and host genotype. Crop Sci. 16: 728-730.

Darlington LC, Mathre DE, Johnston RH. 1977. Variation in pathogenicity between isolates of Claviceps purpurea. Can J Plant Sci. 57: 729-733.

Gabbai, Lisbonne, Pourquier. 1951. Ergot poisoning at Pont St. Esprit. British Medical Journal 2 (4732): 650-651.

Gaudet D, Menzies J, Burnett P. 2000. Smuts, Bunts, and Ergot. Encyclopedia of Microbiology. 4. $2^{\text {nd }}$ ed. San Diego, CA,USA: Academic Press; p. 297-315.

Gordon A, Basler R, Bonsept-Basler P, Fanston V, Harinarayan L, Grant PK, Birchmore R, Bayles R, Boyd L, O'Sullivan DM. 2015. The identification of QTL controlling ergot size in hexaploid wheat implicates a role for the Rht dwarfing alleles. Theor Appl Genet. 128: $2447-2460$.

Kranz J. 2003. Comparative Epidemiology of Plant Diseases. Springer-Verlag, Berlin. 206 pp.

Linder DH. 1948. Fungi, Botany of the Canadian Eastern Artic. Part II. Thallophyta and Bryophyta. Bulletin of the National Museum of Canada 97: 234-297.

Menzies JG. 2004. The reactions of Canadian spring wheat genotypes to inoculation with Claviceps purpurea, the causal agent of ergot. Can J Plant Sci. 84: 625-629.

Menzies JG, Turkington TK. 2014. An overview of the ergot issue in western Canada: Challenges and Solutions. Can J Plant Path. 37: 40-51. 
Pageau D, Collin J, Wauthy J-M. 1994. Une note sure la résistance á l'ergot chez le blé tendre, le blé dur et le triticale. Phytoprotection $75: 45-49$.

Pažoutová S, Pešicová K, Chudíčková M, Šrůtka P, Kolařík M. 2015. Delimitation of cryptic species inside Claviceps purpurea. Fungal Biol. 119: 7-26.

Platford RG, Bernier CC. 1970. Resistance to Claviceps purpurea in spring and durum wheats. Nature 226: 770.

Platford RG, Bernier CC. 1976 Reaction of cultivated cereals to Claviceps purpurea. Can J Plant Sci. 56: 51-58.

Platford RG, Bernier CC, Evans LE. 1977. Chromosome location of genes conditioning resistance to Claviceps purpurea in spring and durum wheat. Can J Genet Cytol. 19: 679682.

Popovic Z, Menzies JG. 2006. Intensive and extensive sampling techniques used to measure genetic diversity of Ustilago tritici, using virulence and DNA polymorphism. Can J Plant Path. 28: 197-207.

Puranik SB, Mathre DE. 1971. Biology and control of ergot on male sterile wheat and barley. Phytopathology 61: 1075-1080.

R Core Team. 2016. R: A Language and Environment for Statistical Computing. R Foundation for Statistical Computing. Vienna, Austria. http://www.R-project.org.

Rapilly F. 1968. Études sur l'ergot du blé : Claviceps purpurea (Fr.) Tul. Annales des épiphyties 19: $305-329$. 
485 Savary S, Madden LV, Zadoks JC, Klein-Gebbinck HW. 1994. Use of categorical information 486 and correspondence analysis in plant disease epidemiology. Adv Bot Res. 21: 213-240.

487 Watkins JE, Littlefield LJ. 1976. Relationship of anthesis in Waldron wheat to infection by 488 Claviceps purpurea. Trans Brit Mycol Soc. 66: 362-363. 
J.G. Menzies et al. Claviceps purpurea and wheat relationships

Table 1. Single spore isolates of Claviceps purpurea (Fr.) Tul. assessed for pathogenic variation on lines of hexaploid wheat (Triticum aestivum L.) and durum wheat (T. turgidum L. var. durum).

\begin{tabular}{|c|c|c|c|}
\hline Isolate & Year of isolation & Location of collection & Host source \\
\hline $7-1^{\mathrm{a}}\left(250621^{\mathrm{b}}\right)$ & 1996 & MB07 ${ }^{\mathrm{C}}$ & $\begin{array}{c}\text { Triticale } \\
\text { (X Triticosecale) }\end{array}$ \\
\hline $7-2(250622)$ & 1996 & MB07 & Triticale \\
\hline $7-3(250623)$ & 1996 & MB07 & Triticale \\
\hline $22(250627)$ & 1996 & MB07 & Barley \\
\hline $24(250628)$ & 1996 & $\mathrm{AB} 05$ & Barley \\
\hline $29-2(250632)$ & 1996 & SK09 & Barley \\
\hline $33-2(250636)$ & 2000 & $\mathrm{AB} 05$ & Barley \\
\hline 38 & 1997 & MB07 & Barley \\
\hline $40(250638)$ & 1997 & SK08 & Barley \\
\hline $44-2(250641)$ & 1997 & MB09 & Barley \\
\hline 77 (250646) & 2000 & SK03 & Wheat \\
\hline $85(250648)$ & 2000 & AB04 & Wheat \\
\hline 89-1 (250649) & 2000 & SK01 & Rye \\
\hline 90 (250650) & 2000 & SK08 & Rye \\
\hline 93-2 & 2000 & MB01 & Rye \\
\hline $95(250652)$ & 2000 & MB01 & Rye \\
\hline 97 & 2000 & $\mathrm{AB} 07$ & Wheat \\
\hline
\end{tabular}




\begin{tabular}{|c|c|c|c|}
\hline $98(250653)$ & 2000 & MB01 & Durum Wheat \\
\hline 100 & 2000 & MB01 & Wheat \\
\hline 101 & 2000 & MB01 & Rye \\
\hline 102 & 2000 & MB03 & Wheat \\
\hline 115 (250657) & 2000 & MB07 & Winter Wheat \\
\hline $125(250658)$ & 2000 & SK01 & Durum Wheat \\
\hline $128(250659)$ & 2000 & SK02 & \begin{tabular}{|l} 
Durum Wheat \\
\end{tabular} \\
\hline 138 & 2000 & SK05 & Wheat \\
\hline 148 & 2000 & SK07 & $\begin{array}{l}\text { Rye } \\
\text { (Secale cereale L.) }\end{array}$ \\
\hline $150(250661)$ & 2000 & SK08 & Durum Wheat \\
\hline 155 & 2000 & SK08 & Durum Wheat \\
\hline $166-1$ & 2000 & $\mathrm{AB} 01$ & Durum Wheat \\
\hline $169-1(250664)$ & 2000 & $\mathrm{AB} 02$ & Durum Wheat \\
\hline $169-6(250668)$ & 2000 & $\mathrm{AB} 02$ & Durum Wheat \\
\hline 172 & 2000 & $\mathrm{AB} 02$ & Wheat \\
\hline $179-1$ (250670) & 2000 & $\mathrm{AB} 04$ & Rye \\
\hline $179-2(250671)$ & 2000 & $\mathrm{AB} 04$ & Rye \\
\hline $179-3(250675)$ & 2000 & $\mathrm{AB} 04$ & Rye \\
\hline $192-1$ (250678) & 2005 & MB07 & Oats \\
\hline $192-4(250679)$ & 2005 & MB07 & Oats \\
\hline UK 03-20-1 & 2003 & Cambridge U.K. & Wheat \\
\hline UK 03-43-1 (250717) & 2003 & Cambridge, U.K. & \begin{tabular}{|l} 
Winter Wheat \\
\end{tabular} \\
\hline
\end{tabular}




\begin{tabular}{|l|l|l|l|}
\hline UK 04-02-1 & 2004 & Cambridge, U.K. & $\begin{array}{l}\text { Blackgrass } \\
\text { (Alopecurus } \\
\text { myosuroides Huds.) }\end{array}$ \\
\hline UK 04-97-1 & 2004 & Cambridge, U.K. & Blackgrass \\
\hline
\end{tabular}

${ }^{a}$ More than one sclerotium could be obtained from one site. The first number represents the

494 collection number and the number following the hyphen represents the number of the sclerotium

495 sampled from that site in the instance of hyphenated isolate designations.

$496{ }^{\mathrm{b}}$ Numbers in brackets are the DAOMC number for those isolates deposited at the Canadian

497 National Mycological Herbarium, Ottawa, ON, Canada.

$498{ }^{\mathrm{c}}$ Unless otherwise indicated, the isolates originated in western Canada. Location of collection for

499 Canadian isolates indicates the provincial crop districts in Manitoba (MB), Saskatchewan (SK), 500 and Alberta (AB). 
502 503

504

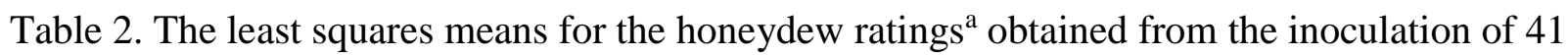
single spore strains of Claviceps purpurea (Fr.) Tul. onto three lines of durum wheat (T. turgidum L. var. durum) and five lines of hexaploid wheat (Triticum aestivum L.).

\begin{tabular}{|c|c|c|c|c|c|c|c|c|}
\hline \multirow{2}{*}{$\begin{array}{l}\text { Fungal } \\
\text { Strain }\end{array}$} & \multicolumn{3}{|c|}{ Durum Wheat line } & \multicolumn{5}{|c|}{ Hexaploid Wheat Line } \\
\hline & $\begin{array}{c}\text { 9260B- } \\
173 \mathrm{~A}\end{array}$ & 'Kyle' & 'Melita' & HY630 & $\begin{array}{l}\text { 'Kenya } \\
\text { Farmer' }\end{array}$ & 'Lee' & 'Vista' & 'Cadillac' \\
\hline $7-1$ & 1 & 3.2 & 3.7 & 1.9 & 1.4 & 2.7 & 2.7 & 2.9 \\
\hline $7-2$ & 1 & 2.7 & 3.9 & 1.6 & 1.2 & 3.4 & 2.9 & 2.4 \\
\hline $7-3$ & 2.2 & 1.9 & 3.7 & 2 & 1.7 & 2.9 & 1.9 & 2.9 \\
\hline 22 & 1 & 1.4 & 2.7 & 1 & 1 & 1.4 & 1.4 & 1.7 \\
\hline 24 & 1.7 & 2.2 & 2.9 & 1.3 & 2.4 & 1.2 & 1.7 & 2.9 \\
\hline $29-2$ & 1.4 & 2.4 & 3.4 & 1 & 1.2 & 2.4 & 1.7 & 1.9 \\
\hline $33-2$ & 1 & 1.4 & 3.4 & 1.9 & 1.4 & 2.7 & 1.4 & 2.7 \\
\hline 38 & 1 & 1 & 3.2 & 1 & 1 & 1.4 & 1.9 & 1 \\
\hline 40 & 1 & 2.7 & 2.7 & 1.9 & 1 & 1.4 & 2.7 & 1.9 \\
\hline $44-2$ & 1 & 2.2 & 3.4 & 3 & 2.2 & 2.9 & 3.4 & 2.9 \\
\hline 77 & 1 & 2.5 & 3.9 & 1 & 1 & 1.5 & 2.6 & 2.1 \\
\hline 85 & 1.9 & 1.9 & 3.9 & 2.3 & 1.7 & 2.9 & 2.7 & 2.9 \\
\hline 89-1 & 1.7 & 2.7 & 3.9 & 3.4 & 3.2 & 3.7 & 3.7 & 3.9 \\
\hline 90 & 1 & 2.9 & 3.4 & 3.4 & 2.9 & 2.9 & 3.4 & 3.7 \\
\hline 93-2 & 1 & 2.9 & 3.4 & 3.7 & 3.4 & 3.7 & 3.7 & 3.9 \\
\hline 95 & 1 & 2.9 & 3.7 & 3.7 & 2.9 & 3.7 & 3.9 & 3.7 \\
\hline
\end{tabular}


J.G. Menzies et al. Claviceps purpurea and wheat relationships

\begin{tabular}{|c|c|c|c|c|c|c|c|c|}
\hline 97 & 1 & 1.2 & 1.7 & 2.5 & 1 & 1.2 & 1.4 & 1 \\
\hline 98 & 2.4 & 1.9 & 2.7 & 1.5 & 1 & 1.7 & 1.9 & 2.2 \\
\hline 100 & 1 & 2.7 & 2.9 & 1.5 & 1 & 1.2 & 2.2 & 1.2 \\
\hline 101 & 1 & 3.4 & 3.7 & 3.4 & 3.2 & 3.9 & 3.9 & 3.9 \\
\hline 102 & 1 & 2.2 & 3.2 & 2.3 & 1 & 2.7 & 2.7 & 2.9 \\
\hline 115 & 1 & 1.2 & 2.7 & 1.5 & 1 & 1.7 & 2.7 & 2.7 \\
\hline 125 & 1 & 2.4 & 3.9 & 2 & 1.9 & 3.2 & 2.9 & 2.9 \\
\hline 128 & 1 & 2.4 & 3.2 & 1 & 1.9 & 2.4 & 2.7 & 2.9 \\
\hline 138 & 2.9 & 1.4 & 2.2 & 2.9 & 1 & 2.2 & 2.4 & 1.9 \\
\hline 148 & 1 & 3.4 & 3.4 & 3.4 & 3.2 & 3.4 & 2.7 & 3.7 \\
\hline 150 & 1 & 1.9 & 3.7 & 1 & 1.2 & 1.4 & 1 & 2.7 \\
\hline 155 & 1.2 & 3.4 & 3.9 & 3 & 2.7 & 2.7 & 3.9 & 3.9 \\
\hline 166-1 & 1 & 3.4 & 3.9 & 1.9 & 1.7 & 3.2 & 3.2 & 2.9 \\
\hline 169-1 & 3.2 & 3.2 & 3.9 & 3.9 & 3.2 & 3.4 & 3.9 & 3.9 \\
\hline $169-6$ & 1 & 3.4 & 3.4 & 3.7 & 3.2 & 3.2 & 3.4 & 3.2 \\
\hline 172 & 1 & 2.4 & 2.9 & 2 & 1 & 1 & 1.2 & 1.2 \\
\hline $179-1$ & 1 & 2.2 & 3.4 & 3 & 2.2 & 2.9 & 3.4 & 2.9 \\
\hline $179-2$ & 1 & 3.9 & 3.9 & 3.9 & 3.4 & 3.7 & 3.9 & 3.9 \\
\hline $179-3$ & 2.4 & 3.5 & 3.9 & 2.7 & 1 & 1.9 & 2.2 & 1.9 \\
\hline $192-1$ & 1.9 & 2.9 & 3.4 & 1.9 & 1 & 1.2 & 1.7 & 1 \\
\hline $192-4$ & 1 & 1.2 & 3.2 & 2.9 & 1.4 & 2.4 & 2.9 & 1.9 \\
\hline $\begin{array}{c}\text { UK 03- } \\
20-1\end{array}$ & 2 & 2.9 & 3.9 & 3.4 & 2.7 & 2.9 & 3.7 & 3.4 \\
\hline
\end{tabular}




\begin{tabular}{|c|c|c|c|c|c|c|c|c|}
\hline UK 03- & 3.6 & 2.6 & 3.9 & 2.8 & 2.9 & 3 & 3.6 & 3 \\
$43-1$ & & & & & & & & \\
\hline UK 04- & 3.5 & 3 & 3.8 & 3.2 & 2.8 & 3.4 & 4 & 3.6 \\
$02-1$ & & & & & & & & \\
\hline UK 04- & 3.2 & 2.4 & 3.7 & 2.2 & 2.4 & 3.2 & 2.7 & 3.7 \\
$97-1$ & & & & & & & & \\
\hline
\end{tabular}

$505{ }^{a}$ Honeydew Rating Scale was 1 = none visible, 2 = honeydew confined within the glumes, $3=$

506 honeydew exuding from the florets in small drops, 4 = large drops of honeydew running down

507 the spikes (Menzies, 2004). An isolate of $C$. purpurea was considered virulent on a wheat line if 508 it caused a honeydew production rating of 2.1 or greater. 
511 Table 3. The least squares means of the weight $(\mathrm{mg})$ of sclerotia per spike obtained from the inoculation of 41 single spore strains of Claviceps purpurea (Fr.) Tul. onto three lines of durum wheat (T. turgidum L. var. durum) and five lines of hexaploid wheat (Triticum aestivum L.).

\begin{tabular}{|c|c|c|c|c|c|c|c|c|}
\hline \multirow{2}{*}{$\begin{array}{l}\text { Fungal } \\
\text { Strain }\end{array}$} & \multicolumn{3}{|c|}{ Durum Wheat line } & \multicolumn{5}{|c|}{ Hexaploid Wheat Line } \\
\hline & $\begin{array}{c}9260 \mathrm{~B}- \\
173 \mathrm{~A}\end{array}$ & 'Kyle' & 'Melita' & HY630 & $\begin{array}{l}\text { 'Kenya } \\
\text { Farmer' }\end{array}$ & 'Lee' & 'Vista' & 'Cadillac' \\
\hline $7-1$ & $3^{a}$ & 80 & 78 & 8 & 30 & 93 & 244 & 188 \\
\hline $7-2$ & 3 & 10 & 139 & 21 & 34 & 132 & 271 & 97 \\
\hline $7-3$ & 48 & 14 & 288 & 104 & 31 & 152 & 192 & 260 \\
\hline 22 & 0 & 2 & 41 & 13 & 0 & 23 & 95 & 102 \\
\hline 24 & 22 & 16 & 66 & 9 & 209 & 55 & 155 & 132 \\
\hline $29-2$ & 3 & 35 & 155 & 12 & 36 & 186 & 144 & 128 \\
\hline $33-2$ & 6 & 6 & 93 & 15 & 46 & 281 & 130 & 99 \\
\hline 38 & 0 & 4 & 33 & 6 & 4 & 23 & 184 & 19 \\
\hline 40 & 2 & 10 & 169 & 54 & 33 & 74 & 190 & 75 \\
\hline $44-2$ & 71 & 43 & 319 & 93 & 169 & 291 & 536 & 306 \\
\hline 77 & 2 & 44 & 169 & 2 & 8 & 17 & 125 & 47 \\
\hline 85 & 10 & 18 & 84 & 60 & 44 & 424 & 489 & 357 \\
\hline $89-1$ & 5 & 27 & 185 & 297 & 604 & 368 & 514 & 714 \\
\hline 90 & 9 & 124 & 337 & 412 & 691 & 538 & 734 & 1179 \\
\hline
\end{tabular}


J.G. Menzies et al. Claviceps purpurea and wheat relationships

\begin{tabular}{|c|c|c|c|c|c|c|c|c|}
\hline $93-2$ & 2 & 102 & 260 & 472 & 747 & 444 & 682 & 1150 \\
\hline 95 & 18 & 39 & 641 & 218 & 253 & 257 & 579 & 870 \\
\hline 97 & 17 & 4 & 54 & 94 & 19 & 40 & 82 & 50 \\
\hline 98 & 20 & 17 & 57 & 92 & 134 & 295 & 246 & 75 \\
\hline 100 & 18 & 41 & 158 & 28 & 6 & 21 & 191 & 83 \\
\hline 101 & 40 & 98 & 630 & 323 & 278 & 505 & 543 & 619 \\
\hline 102 & 0 & 7 & 61 & 29 & 7 & 127 & 57 & 183 \\
\hline 115 & 0 & 10 & 47 & 19 & 43 & 145 & 149 & 250 \\
\hline 125 & 23 & 174 & 674 & 25 & 81 & 217 & 380 & 497 \\
\hline 128 & 3 & 6 & 96 & 24 & 46 & 225 & 231 & 259 \\
\hline 138 & 80 & 6 & 141 & 146 & 16 & 324 & 109 & 190 \\
\hline 148 & 2 & 169 & 550 & 371 & 681 & 543 & 335 & 978 \\
\hline 150 & 0 & 17 & 101 & 0 & 14 & 52 & 75 & 101 \\
\hline 155 & 2 & 48 & 304 & 184 & 156 & 345 & 397 & 557 \\
\hline 166-1 & 9 & 424 & 777 & 9 & 224 & 371 & 400 & 524 \\
\hline 169-1 & 92 & 77 & 997 & 440 & 399 & 426 & 842 & 911 \\
\hline 169-6 & 16 & 33 & 272 & 290 & 617 & 168 & 580 & 454 \\
\hline 172 & 4 & 40 & 90 & 113 & 28 & 50 & 130 & 62 \\
\hline 179-1 & 17 & 125 & 638 & 481 & 449 & 420 & 765 & 1201 \\
\hline 179-2 & 13 & 400 & 925 & 257 & 469 & 535 & 704 & 853 \\
\hline 179-3 & 99 & 206 & 514 & 126 & 4 & 49 & 55 & 204 \\
\hline 192-1 & 59 & 133 & 195 & 24 & 2 & 41 & 83 & 31 \\
\hline $192-4$ & 27 & 25 & 287 & 139 & 25 & 82 & 164 & 49 \\
\hline
\end{tabular}


J.G. Menzies et al. Claviceps purpurea and wheat relationships

\begin{tabular}{|c|c|c|c|c|c|c|c|c|}
\hline UK 03- & 59 & 103 & 320 & 118 & 49 & 91 & 420 & 13 \\
$20-1$ & & & & & & & & \\
\hline UK 03- & 212 & 31 & 356 & 238 & 272 & 188 & 282 & 250 \\
U3-1 & & & & & & & & \\
02-1 & 195 & 142 & 278 & 115 & 133 & 130 & 457 & 531 \\
\hline UK 04- & 129 & 31 & 377 & 107 & 57 & 143 & 64 & 316 \\
\hline $97-1$ & & & & & & & & \\
\hline
\end{tabular}

515 an isolate of $C$. purpurea was considered virulent on a wheat line if it caused a sclerotial weight

516 per spike of $81 \mathrm{mg}$ or greater.

517

518 
Figure 1. Correspondence analysis biplot of the contingency table involving wheat differential line, isolate sampling location and isolate host source for honeydew production ( $\mathrm{H} 1$ to H4). The graph is derived from the eigenanalysis of these contingency tables. The first eigenvector accounted for $73.2 \%$ of the variation in the contingency tables, and the second eigenvector accounted for $23.2 \%$ of the variation. The path from $\mathrm{H} 1$ to $\mathrm{H} 4$ indicates increasing honeydew production with means of 1.0, 2.0, 3.0 and 4.0 for $\mathrm{H} 1, \mathrm{H} 2$, H3 and H4, respectively. Wheat differential lines; 9260B-173A (9260B), 'Kyle', 'Melita', HY630, 'Kenya Farmer', 'Lee', 'Vista', 'Cadillac'. Isolate sampling location; United Kingdom (UK), Alberta (AB), Saskatchewan (SK), Manitoba (MB). Isolate host source; rye (Rye), blackgrass (BG), triticale (Tri), durum wheat (Dur), hexaploid wheat (Wht), oats (Oat), barley (Bar).

Figure 2. Correspondence analysis biplot of the contingency table involving wheat differential line, isolate sampling location and isolate host source for sclerotial weight per spike (Sc1 to Sc4). The graph is derived from the eigenanalysis of these contingency tables. The first eigenvector accounted for $80.9 \%$ of the variation in the contingency tables, and the second eigenvector accounted for $16.3 \%$ of the variation. The path from Sc1 to Sc4 indicates increasing sclerotial weight with means of 11.2, 80.1, 226.9 and 610.5 for Sc1, Sc2, Sc3 and Sc4, respectively. Wheat differential lines; 9260B-173A (9260B), 'Kyle', 'Melita', HY630, 'Kenya Farmer', 'Lee', 'Vista', 'Cadillac'. Isolate sampling location; United Kingdom (UK), Alberta (AB), Saskatchewan (SK), Manitoba (MB). Isolate host source; rye (Rye), blackgrass (BG), triticale (Tri), durum wheat (Dur), hexaploid wheat (Wht), oats (Oat), barley (Bar). 


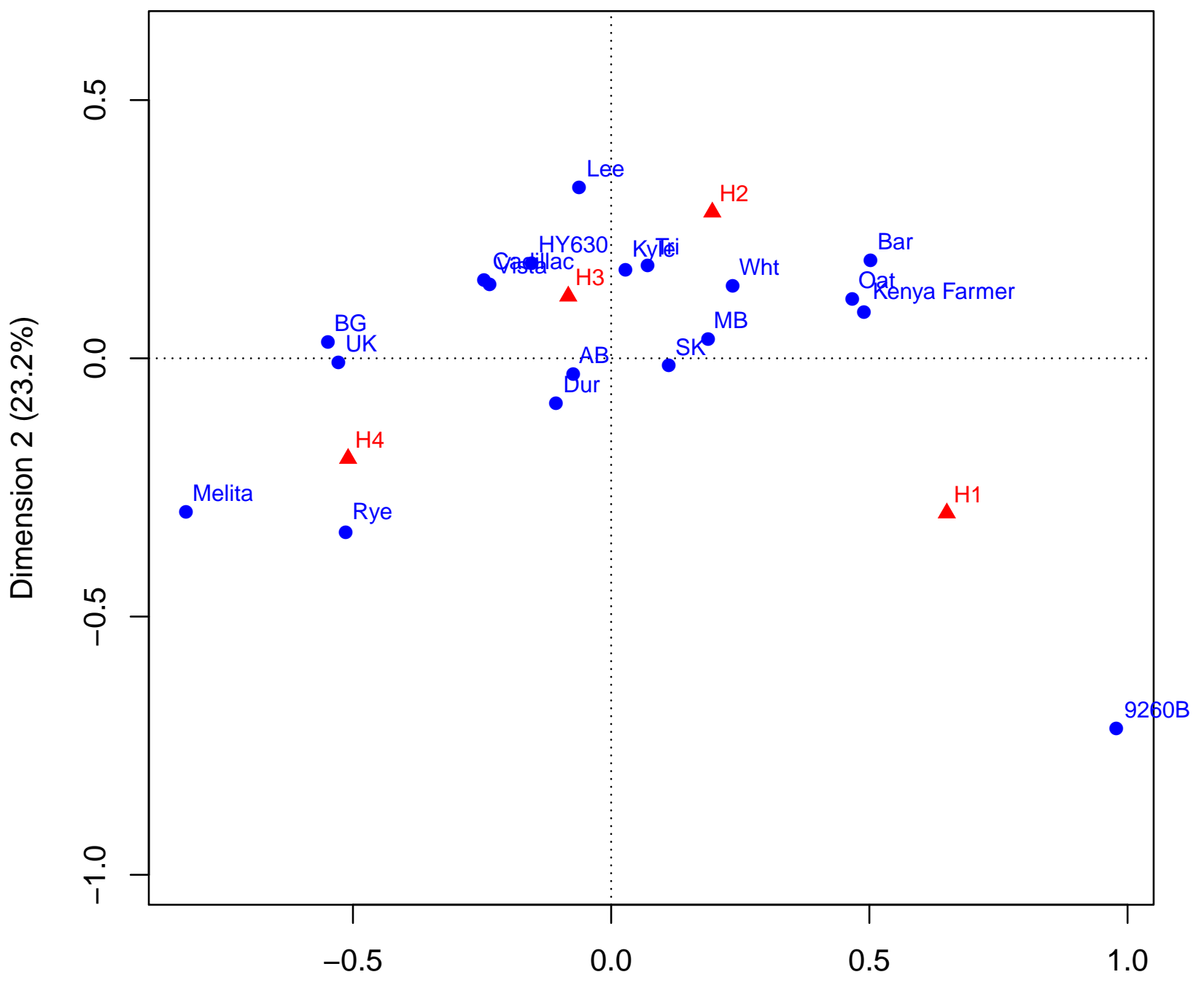

Dimension 1 (73.2\%) 


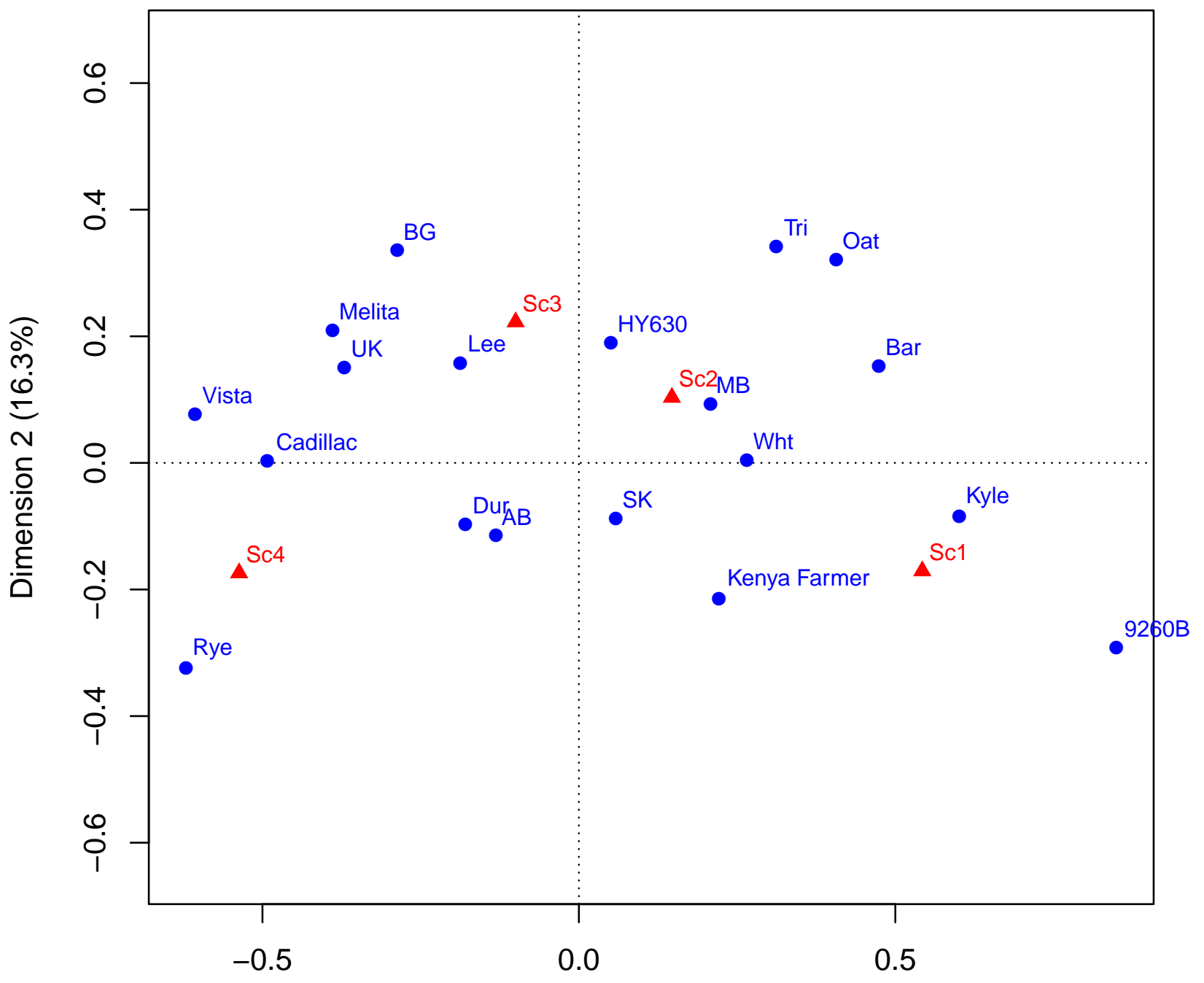

Dimension 1 (80.9\%) 